\title{
On the Microfoundation of Linear Oligopoly Demand
}

Citation for published version (APA):

Bos, I., \& Vermeulen, D. (2019). On the Microfoundation of Linear Oligopoly Demand. Maastricht University, Graduate School of Business and Economics. GSBE Research Memoranda No. 004 https://doi.org/10.26481/umagsb.2019004

Document status and date:

Published: 28/01/2019

DOI:

10.26481/umagsb.2019004

Document Version:

Publisher's PDF, also known as Version of record

\section{Please check the document version of this publication:}

- A submitted manuscript is the version of the article upon submission and before peer-review. There can be important differences between the submitted version and the official published version of record.

People interested in the research are advised to contact the author for the final version of the publication, or visit the DOI to the publisher's website.

- The final author version and the galley proof are versions of the publication after peer review.

- The final published version features the final layout of the paper including the volume, issue and page numbers.

Link to publication

\footnotetext{
General rights rights.

- You may freely distribute the URL identifying the publication in the public portal. please follow below link for the End User Agreement:

www.umlib.nl/taverne-license

Take down policy

If you believe that this document breaches copyright please contact us at:

repository@maastrichtuniversity.nl

providing details and we will investigate your claim.
}

Copyright and moral rights for the publications made accessible in the public portal are retained by the authors and/or other copyright owners and it is a condition of accessing publications that users recognise and abide by the legal requirements associated with these

- Users may download and print one copy of any publication from the public portal for the purpose of private study or research.

- You may not further distribute the material or use it for any profit-making activity or commercial gain

If the publication is distributed under the terms of Article $25 \mathrm{fa}$ of the Dutch Copyright Act, indicated by the "Taverne" license above, 


\section{Maastricht University}

Iwan Bos, Dries Vermeulen

On the Microfoundation of Linear Oligopoly Demand

$\mathrm{RM} / 19 / 004$

\section{GSBE}

Maastricht University School of Business and Economics

Graduate School of Business and Economics

P.O Box 616

NL- 6200 MD Maastricht

The Netherlands 


\title{
On the Microfoundation of Linear Oligopoly Demand
}

\author{
Iwan Bos* Dries Vermeulen ${ }^{\dagger}$
}

January 25, 2019

\begin{abstract}
We critically assess the representative consumer model that forms the foundation of a well-known class of linear oligopoly demand structures. It is argued that this approach has several limitations. We present an alternative microeconomic foundation by deriving the same demand system directly from a population of heterogeneous buyers. Our approach can be easily adapted to different demand specifications.

Keywords: Microfoundations; Oligopoly Theory; Product Differentiation; Representative Consumer Models.

JEL Codes: B4; L1.
\end{abstract}

* Department of Organization \& Strategy, Maastricht University. Corresponding author at: P.O. Box 616, 6200 MD Maastricht, The Netherlands. E-mail: i.bos@maastrichtuniversity.nl.

${ }^{\dagger}$ Department of Quantitative Economics, Maastricht University. 


\section{Introduction}

A well-known way of describing the buyers' side of an oligopoly market is through a linear horizontally differentiated demand model. For the case of duopoly, the (direct) demand structure generally takes the following form:

$$
\begin{aligned}
& x_{1}\left(p_{1}, p_{2}\right)=a_{1}-b_{1} \cdot p_{1}+c \cdot p_{2}, \\
& x_{2}\left(p_{1}, p_{2}\right)=a_{2}-b_{2} \cdot p_{2}+c \cdot p_{1},
\end{aligned}
$$

where price and quantity are positive and respectively given by $p_{i}$ and $x_{i}$, for $i=1,2 .{ }^{1}$ It is, moreover, commonly assumed that $a_{i}, b_{i}, c>0$ and $b_{i}>c$, for $i=1,2$, so that a firm's demand depends negatively on its own price, positively on the rival's price and own effects dominate cross effects. This demand system can be roughly interpreted as follows. If, say, firm 1 raises its price slightly, then ceteris paribus some of its customers walk away and either go home or visit firm 2 instead. Likewise, lowering price attracts additional buyers, some of whom switch from the competing firm.

The traditional foundation for this demand specification does not come from a group of heterogeneous buyers, however, but from a representative consumer who on behalf of an unspecified buyer population maximizes a quadratic aggregate welfare function. The most popular variations of this type are due to Bowley (1924) and Shubik and Levitan (1980). ${ }^{2}$

In the field of macroeconomics, such a representative agent approach has been heavily criticized by many. One reason for this is that transforming individual preferences into representative aggregate preferences often proves problematic. It is, for instance, quite possible that the representative agent prefers A to B, whereas each and every represented buyer prefers B to A. ${ }^{3}$ For this and other reasons, many macroeconomists are reluctant to take this approach and some even went as far as to effectively compose a requiem for the representative consumer. ${ }^{4}$ This is in stark contrast to the fields of microeconomics and industrial organization, where the use of such a fictitious agent is widely accepted. What makes this particularly

\footnotetext{
${ }^{1}$ See, for instance, Singh and Vives (1984). This setting can be easily generalized to an $n$-firm variant. See, for example, Häckner (2000).

${ }^{2}$ See Martin (2002) for a detailed discussion of both these models.

${ }^{3}$ This Pareto inconsistency has been clearly established by Jerison (1984). See also Dow and da Costa Werlang (1988).

${ }^{4}$ See, for example, Kirman (1992).
} 
surprising is that a rationale for this approach is commonly missing. ${ }^{5}$

In this paper, we have two main goals. The first is to provide a critical assessment of the representative consumer as a foundation for the above linear demand structure. Specifically, we argue that it is both inaccurate and inadequate. It is inaccurate as the representative agent's aggregate utility function has no (clear) connection with the objectives of those represented. ${ }^{6}$ It is inadequate because a justification for both the utility specification and the solution approach is missing. Taken together, this leads us to conclude that the popular linear oligopoly demand structure lacks a proper foundation.

We then proceed with our second goal, which is to argue that quadratic representative consumer models are effectively redundant. We do so by showing that the same demand structure can be easily derived directly from a population of heterogeneous consumers. A main advantage of this approach is that it is explicitly based on simple buyer behavior at the micro-level and therefore has a natural interpretation.

A couple of recent papers have raised some red flags regarding the use of a representative agent with a quadratic utility function. Kopel, Ressi and Lambertini (2017), for instance, show that seemingly similar quadratic aggregate utility functions may give rise to fundamentally different demand systems. In turn, this might lead to radically different policy implications. Amir, Erickson and Jin (2017) provide a thorough study of several characteristics of the quadratic utility specification. Among other things, they establish that strict concavity of the utility function is a necessary condition for the corresponding demand system to be welldefined.

The remainder of this paper is organized as follows. The next section discusses the quadratic representative consumer utility function and highlights several problematic features of this specification. Section 3 presents a microfoundation for linear oligopoly demand. Section 4 concludes.

\footnotetext{
${ }^{5}$ As a telling example, both Bowley (1924) and Shubik and Levitan (1980) introduce this approach as an illustration and do not provide an explanation or justification for the specification of their representative consumer's utility function.

${ }^{6}$ The exception here would be when the population of represented buyers is assumed to all possess the same utility function. Yet, in that particular case it is not clear what exactly would be the added value of a representative agent.
} 


\section{Quadratic Representative Consumer Models}

In this section, we express some concerns about the above mentioned class of quadratic representative consumer models. Specifically, we raise several issues regarding the shape of the objective function, the derivation of the corresponding demand functions and the relation between the products involved.

\subsection{Issue 1: the Objective}

Both the Bowley (1924) and the Shubik-Levitan (1980) demand specifications are derived from a representative consumer gross utility function that takes the following general form:

$$
U\left(x_{1}, x_{2}\right)=\alpha \cdot\left(x_{1}+x_{2}\right)-\beta \cdot\left(x_{1}+x_{2}\right)^{2}-\gamma \cdot\left(x_{2}-x_{1}\right)^{2},
$$

with $\alpha, \beta, \gamma>0 .{ }^{7}$ Notice that the way in which we present the objective function, it effectively consists of three distinct parts. Starting with the third, $\gamma \cdot\left(x_{2}-x_{1}\right)^{2}$, this part captures the complementarity between both products. Consistent with classic consumer theory, utility is ceteris paribus higher with a more balanced consumption plan. In fact, the representative agent is induced to buy both products in equal amounts $\left(x_{1}=x_{2}\right)$ so that the third-term disutility is minimized and de facto disappears.

The first two parts, $\alpha \cdot\left(x_{1}+x_{2}\right)-\beta \cdot\left(x_{1}+x_{2}\right)^{2}$, capture utility coming from total rather than relative consumption and express the extent to which the goods are considered substitutes. These components indicate that the consumer derives utility from consuming more products, but only up to a certain amount. That is, utility increases at low levels of total consumption through the first term, but at higher levels of total consumption the second term starts to dominate the first. This implies that there is a point at which the consumer is satiated. Notice that this holds even when the representative consumer would not face a budget constraint. Contrary to the third term favoring balance in consumption, this therefore is at odds with traditional consumer theory. ${ }^{8}$ Indeed, the fact that the objective function has a unique maximum makes that the common assumption of nonsatiation is violated.

\footnotetext{
${ }^{7}$ See Bowley (1924, p.56) and Shubik and Levitan (1980, p.69).

${ }^{8}$ See, for instance, Chapter 1 of Jehle and Reny (2001) for a detailed discussion of classic consumer theory.
} 


\subsection{Issue 2: the Solution}

To solve the representative consumer problem, one naturally needs to take account of the cost of consumption. In the following, we point out that the linear oligopoly demand structure will only result from the representative agent's maximization problem under fairly specific, and arguably strong, assumptions.

Towards that end, let $F$ be a set of vectors $(x, m) \in \mathbb{R}^{n} \times \mathbb{R}$ and consider the utility function $V: F \mapsto \mathbb{R}$. For $(x, m) \in F$, therefore, utility $V(x, m)$ is obtained from consuming an amount of $x \in \mathbb{R}^{n}$ goods as well as from the unspent money $m$. Moreover, let the vector of prices be given by $p \in \mathbb{R}^{n}$. If the available income is $I \geq 0$, then the representative consumer faces the following general maximization problem:

$$
\begin{array}{rlrl}
\max _{x \in F} & V(x, m) \\
\text { s.t.: } & m=I-p \cdot x, \\
& m \geq 0,
\end{array}
$$

where $p \cdot x$ is total expenditure.

It can be easily verified, however, that the linear oligopoly demand system is the solution to:

$$
\begin{array}{rr}
\max _{x \in F} & U(x)+m \\
\text { s.t.: } & m=I-p \cdot x .
\end{array}
$$

Thus, in light of the general maximization problem, $V(x, m)=U(x)+m$ and the constraint $m \geq 0$ is ignored. Observe that this specification effectively treats expenditures as a disutility, which is linearly subtracted from the gross utility function. At first sight this may seem natural and innocuous, but it does imply two strong assumptions:

[A1] The representative consumer's utility function is quasi-linear in money;

[A2] The representative consumer can borrow unlimited amounts of money for free.

The first condition means the absence of a wealth effect as utility is linearly increasing in money. Irrespective of whether utility is high or low, the marginal gain of an extra dollar is the same. The second states that the budget restriction has no bite and is effectively nonexistent. Indeed, this approach implies that the budget constraint is never binding even when the representative consumer would have no income at all. ${ }^{9}$

\footnotetext{
${ }^{9}$ Amir, Erickson and Jin (2017) point out that the representative consumer's budget should be sufficiently high for an interior solution in which income effects are absent, which is an alternative interpretation of A2.
} 


\subsection{Issue 3: the Products}

Following the textbook approach and thus assuming A1 and A2, the representative consumer picks $x_{1}$ and $x_{2}$ to maximize:

$$
V\left(x_{1}, x_{2}\right)=\alpha \cdot\left(x_{1}+x_{2}\right)-\beta \cdot\left(x_{1}+x_{2}\right)^{2}-\gamma \cdot\left(x_{2}-x_{1}\right)^{2}+I-p_{1} \cdot x_{1}-p_{2} \cdot x_{2},
$$

which gives

$$
\begin{aligned}
& x_{1}=\frac{\alpha}{4 \beta}-\left(\frac{1}{8 \beta}+\frac{1}{8 \gamma}\right) \cdot p_{1}+\left(\frac{1}{8 \gamma}-\frac{1}{8 \beta}\right) \cdot p_{2}, \\
& x_{2}=\frac{\alpha}{4 \beta}-\left(\frac{1}{8 \beta}+\frac{1}{8 \gamma}\right) \cdot p_{2}+\left(\frac{1}{8 \gamma}-\frac{1}{8 \beta}\right) \cdot p_{1} .
\end{aligned}
$$

Goods are substitutes in price when $x_{1}\left(p_{1}, p_{2}\right)$ is increasing in $p_{2}$ and $x_{2}\left(p_{1}, p_{2}\right)$ is increasing in $p_{1}$. Notice that this is the case precisely when $\frac{1}{8 \gamma}>\frac{1}{8 \beta}$, which is equivalent to $\gamma<\beta$.

Goods are substitutes in utility when for every $\eta_{1}>0$ there is an $\eta_{2}>0$ such that:

$$
U\left(x_{1}-\eta_{1}, x_{2}+\eta_{2}\right)=U\left(x_{1}, x_{2}\right)
$$

That is, every decrease in utility resulting from a reduction in the consumption of good 1 can be compensated by an increase in the consumption of good $2 .{ }^{10}$ If we consider $x_{2}$ an implicit function $X_{2}\left(x_{1}\right)$, then $X_{2}^{\prime}<0$. Implicit differentiation yields:

$$
\alpha \cdot\left(1+X_{2}^{\prime}\right)-2 \beta \cdot\left(x_{1}+X_{2}\right) \cdot\left(1+X_{2}^{\prime}\right)-2 \gamma \cdot\left(x_{1}-X_{2}\right) \cdot\left(1-X_{2}^{\prime}\right)=0 .
$$

Rearranging gives:

$$
X_{2}^{\prime}\left(x_{1}\right)=\frac{2 \gamma \cdot\left(x_{1}-x_{2}\right)+2 \beta \cdot\left(x_{1}+x_{2}\right)-\alpha}{2 \gamma \cdot\left(x_{1}-x_{2}\right)-2 \beta \cdot\left(x_{1}+x_{2}\right)+\alpha} .
$$

Thus, $X_{2}^{\prime}<0$ requires

$$
2 \gamma \cdot\left(x_{1}-x_{2}\right)+2 \beta \cdot\left(x_{1}+x_{2}\right)-\alpha<0 \Longrightarrow(\beta+\gamma) \cdot x_{1}+(\beta-\gamma) \cdot x_{2}<\frac{\alpha}{2}
$$

and

$$
2 \gamma \cdot\left(x_{1}-x_{2}\right)-2 \beta \cdot\left(x_{1}+x_{2}\right)+\alpha>0 \Longrightarrow(\beta+\gamma) \cdot x_{2}+(\beta-\gamma) \cdot x_{1}<\frac{\alpha}{2}
$$

or the reverse.

\footnotetext{
${ }^{10} \mathrm{It}$ is noteworthy that there is an alternative interpretation of substitution in utility in the literature that dates back as far as Edgeworth (1881). In that case, two goods, $x$ and $y$, are considered substitutes in utility when $\partial^{2} U / \partial x \partial y<0$ and $\partial^{2} U / \partial y \partial x<0$. It can be easily verified that when both goods are substitutes in utility according to this definition, then they are indeed also substitutes in price and vice versa.
} 
Note that the above inequalities do not hold for all consumption bundles $\left(x_{1}, x_{2}\right)$. For instance, $x_{1}=0, x_{2}=1$ and $\beta-\gamma<\frac{\alpha}{2}<\beta+\gamma$ violates the inequalities. In this model, therefore, products are never pure substitutes or complements. In particular, there is always a combination $\left(x_{1}, x_{2}\right)$ for which $x_{1}$ and $x_{2}$ are complements in utility and substitutes in price. $^{11}$

This is a remarkable result in that one would expect a clear connection between the properties of the utility function and the properties of the corresponding demand structure. This limited explanatory power is particularly problematic since the representative consumer's utility function is ultimately intended to serve as a microfoundation for linear oligopoly demand.

\section{A Microeconomic foundation for Linear Oligopoly Demand}

In the previous section, we have highlighted some problematic features of quadratic representative consumer models. We now proceed by presenting an alternative microfoundation for the linear oligopoly demand structure as described above:

$$
\begin{aligned}
& x_{1}\left(p_{1}, p_{2}\right)=a_{1}-b_{1} \cdot p_{1}+c \cdot p_{2}, \\
& x_{2}\left(p_{1}, p_{2}\right)=a_{2}-b_{2} \cdot p_{2}+c \cdot p_{1} .
\end{aligned}
$$

Specifically, we will show in the following how this demand system can be derived directly from a population of heterogeneous consumers.

To begin, consider a price-setting duopoly where both firms are located on the boundary of an interval $[0,2]$. In particular, and without loss of generality, firm 1 and firm 2 are respectively situated at 0 and 2 . There are three types of consumers, each with uniform population density $\lambda_{i}$ on $[0,2], i=1,2,3$. The total number of type $i$ buyers is thus given by $2 \cdot \lambda_{i}$. Type 1 customers are assumed to obtain positive gross utility when buying from firm $1, s>0$, and no utility when buying from firm 2. By contrast, Type 2 customers attach no value to the products of firm 1 and derive positive gross utility from buying at firm $2, v>0$. Finally, Type 3 customers value both equally and have a willingness to pay of 4 for each. ${ }^{12}$ Consumers buy

\footnotetext{
${ }^{11}$ Indeed, it can be easily verified that the level curves are ellipses. To illustrate, let $\alpha=4$ and $\beta=\gamma$ be (approximately) equal to 1 so that $U=2-\left(x_{1}-1\right)^{2}-\left(x_{2}-1\right)^{2}$. At $U=1$, the indifference curve is therefore a circle with center $\left(x_{1}, x_{2}\right)=(1,1)$ and radius 1 . The goods are then complements at $\left(x_{1}, x_{2}\right)=$ $\left(1+\frac{1}{2} \sqrt{2}, 1-\frac{1}{2} \sqrt{2}\right)$, for example.

${ }^{12}$ As an illustrative interpretation, one may view both firms as competing ice cream vendors where firm
} 
no more than one unit of the product and are characterized by their location. In the spirit of spatial IO settings, there are costs associated with distance between buyer and seller and these are assumed to be linearly increasing.

Let us now specify the utility function of a Type 1 consumer located at $z \in[0,2]$. This customer has basically three options: (1) buy from firm 1 (value $s-z-p_{1}$ ), (2) buy from firm 2 (value $z-2-p_{2}$ ) or (3) buy nothing (value 0 ). Notice that the third choice dominates the second, because $z-2-p_{2} \leq 0$ for positive prices. Thus, the utility function of a Type 1 buyer located at $z \in[0,2]$ effectively is

$$
u_{1}\left(p_{1}, p_{2}, z\right)=\max \left\{s-z-p_{1}, 0\right\}
$$

The Type 1 customer who is indifferent between option (1) and option (3) is located at $z=s-p_{1}$.

The utility function of a Type 2 customer located at $z \in[0,2]$ can be determined in a similar fashion and is given by

$$
u_{2}\left(p_{1}, p_{2}, z\right)=\max \left\{v-2+z-p_{2}, 0\right\} .
$$

The Type 2 customer who is indifferent between buying and not buying is thus located at $z=p_{2}-v+2$. Finally, the utility function of a Type 3 customer at $z \in[0,2]$ is

$$
u_{3}\left(p_{1}, p_{2}, z\right)=\max \left\{4-z-p_{1}, 2+z-p_{2}, 0\right\}
$$

Under the assumption that prices are sufficiently low, the indifferent Type 3 buyer is located at $z=1+\frac{1}{2}\left(p_{2}-p_{1}\right) \cdot{ }^{13}$

On the basis of these utility specifications, we can now derive the corresponding demand functions. For a given combination of prices $\left(p_{1}, p_{2}\right)$ in the relevant range, demand for firm 1 is given by the sum of consuming Type 1 buyers and the part of Type 3 buyers preferring the product of firm $1 .^{14}$

$$
x_{1}\left(p_{1}, p_{2}\right)=\lambda_{1} \cdot\left(s-p_{1}\right)+\lambda_{3} \cdot\left(1+\frac{1}{2}\left(p_{2}-p_{1}\right)\right)
$$

1 sells strawberry flavor and firm 2 sells vanilla ice. Type 1 buyers are then those customers who only like strawberry ice, for example, whereas Type 2 buyers exclusively prefer vanilla. Type 3 customers consider both and let their buying decision depend on the prices set.

${ }^{13}$ A sufficient condition to ensure that all Type 3 consumers buy a product is $p_{1}, p_{2} \leq 2$.

${ }^{14}$ Indifferent Type 1 and Type 2 customers are located in the interval $[0,2]$ when $s-2 \leq p_{1} \leq s$ and $v-2 \leq p_{2} \leq v$. Type 3 customers prefer to buy a product when $p_{1}+p_{2} \leq 6$. 


$$
=s \cdot \lambda_{1}+\lambda_{3}-\left(\lambda_{1}+\frac{1}{2} \lambda_{3}\right) \cdot p_{1}+\frac{1}{2} \lambda_{3} \cdot p_{2} .
$$

Demand for the products of firm 2 can be derived in a similar way.

$$
x_{2}\left(p_{1}, p_{2}\right)=v \cdot \lambda_{2}+\lambda_{3}-\left(\lambda_{2}+\frac{1}{2} \lambda_{3}\right) \cdot p_{2}+\frac{1}{2} \lambda_{3} \cdot p_{1} .
$$

The above approach therefore allows one to derive any linear oligopoly demand structure of the form:

$$
\begin{aligned}
& x_{1}\left(p_{1}, p_{2}\right)=a_{1}-b_{1} \cdot p_{1}+c \cdot p_{2}, \\
& x_{2}\left(p_{1}, p_{2}\right)=a_{2}-b_{2} \cdot p_{2}+c \cdot p_{1},
\end{aligned}
$$

where $\lambda_{1}=b_{1}-c, \lambda_{2}=b_{2}-c, \lambda_{3}=2 c, s=\frac{a_{1}-2 c}{b_{1}-c}$ and $v=\frac{a_{2}-2 c}{b_{2}-c}$.

\section{Concluding Remarks}

The use of representative agents in economic theory dates back at least as far as the late 1800s when Marshall's manuscript Principles of Economics saw the light of day. ${ }^{15}$ Marshall introduced the notion of a 'representative firm', but also considered employing this approach in other areas of economics. ${ }^{16}$ In fact, he is claimed to have said: ${ }^{17}$

"I think the notion of 'representative firm' is capable of extension to labour; and I have had some idea of introducing that into my discussion of standard rates of wages. But I don't feel sure I shall: and I almost think I can say what I want to more simply in another way.."

In this paper, we have shown this hunch might hold true for a well-known class of quadratic representative consumer models. Indeed, one can quite simply derive the corresponding linear oligopoly demand structure directly from a population of heterogeneous buyers. This renders the use of a fictitious agent in this case effectively redundant. Moreover, the resulting microeconomic foundation can be easily extended to other demand specifications.

It is, however, not only for the sake of simplicity that one should pass by this representative buyer model. In line with other recent work discussed above, we have pointed out some

\footnotetext{
${ }^{15}$ The first edition of this work was published in 1890. A flavour of the representative agent approach can also be found in Edgeworth (1925, an English translation of an Italian version from 1897).

${ }^{16}$ A detailed discussion is provided by Hartley (1996).

${ }^{17}$ See Pigou (1956, p. 437). Bold emphasis is ours.
} 
problematic traits of this approach. In particular, we have argued that it is inaccurate as the representative agent's aggregate utility function has no clear connection with the represented buyers' objectives and that it is inadequate as it requires an unsatisfactory solution approach to obtain the linear oligopoly demand system. Moreover, it is quite possible that substitutability in prices embedded in the demand structure corresponds to products that the representative consumer considers complements. Together, this should raise strong doubts about welfare analyses based on this type of representative consumer models. It also naturally warrants critical assessment of other settings with a similar approach (e.g., constant elasticity of substitution (CES) models). ${ }^{18}$ We leave this issue for future research.

\footnotetext{
${ }^{18}$ For this type of representative consumer model, see Dixit and Stiglitz (1977).
} 


\section{References}

[1] Amir, Rabah, Philip Erickson and Jim Jin (2017), "On the Microeconomic Foundations of Linear Demand for Differentiated Products," Journal of Economic Theory, 169, 641665

[2] Bowley, Arthur L. (1924), "The Mathematical Groundwork of Economics," Oxford University Press;

[3] Dixit, Avinash K. and Joseph E. Stiglitz (1977), "Monopolistic Competition and Optimum Product Diversity," American Economic Review, 67(3), 297-308;

[4] Dow, James and Sergio Ribeiro da Costa Werlang (1988), "The Consistency of Welfare Judgements with a Representative Consumer," Journal of Economic Theory, 44(2), 269280 ;

[5] Edgeworth, Francis Y. (1881), "Mathematical Physics: An Essay on the Application of Mathematics to the Moral Sciences," C. Kegan Paul \& Co.: London;

[6] Edgeworth, Francis Y. (1925), "The Pure Theory of Monopoly," Papers Relating to Political Economy, 1, 111-142;

[7] Häckner, Jonas (2000), "A Note on Price and Quantity Competition in Differentiated Oligopolies," Journal of Economic Theory, 93(2), 233-239;

[8] Hartley, James E. (1996), "Retrospectives: The Origins of the Representative Agent," Journal of Economic Perspectives, 10(2), 169-177;

[9] Jehle, Geoffrey A. and Philip J. Reny (2001), "Advanced Microeconomic Theory," 2nd edition, University of Chicago, Addison-Wesley Longman, inc.;

[10] Jerison, Michael (1984), "Social Welfare and the Unrepresentative Representative Consumer," Discussion Paper, SUNY Albany;

[11] Kirman, Alan P. (1992), "Whom or What does the Representative Individual Represent?," Journal of Economic Perspectives, 6(2), 117-136; 
[12] Kopel, Michael, Anna Ressi and Luca Lambertini (2017), "Capturing Direct and Cross Price Effects in a Differentiated Products Duopoly Model," The Manchester School, 85(3), 282-294;

[13] Marshall, Alfred (1920), "Principles of Economics," 8th edition, Macmillan and Co, London;

[14] Pigou, Arthur C., edited by, (1956), "Memorials of Alfred Marshall," Kelly Millman, New York;

[15] Shubik, Martin and Richard Levitan (1980), "Market Structure and Behavior," Harvard University Press;

[16] Singh, Nirvikar and Xavier Vives (1984), "Price and Quantity Competition in a Differentiated Duopoly," RAND Journal of Economics, 15(4), 546-554;

[17] Martin, Stephen (2002), “Advanced Industrial Economics," 2nd edition, Blackwell Publishing. 